\title{
Caracterização da ventilação natural em Tangará da Serra/MT, Brasil sob o viés da construção civil
}

A ventilação natural é, no Brasil, uma importante estratégia bioclimática para a promoção de conforto térmico em edificações. Este trabalho tem como objetivo desenvolver e avaliar a velocidade e direção dos ventos no município de Tangará da Serra - MT, com o intuito de contribuir como acervo científico de pesquisa para a concepção de projetos de arquitetura bioclimática. Para tanto, utilizou-se de dados de 2004 a 2014, fornecidos pelo Instituto Nacional de Meteorologia INMET, a partir dos quais foram estabelecidos médias horários para cada dia do ano. Com isto, os resultados foram inseridos no software WRPlot, o qual fornece gráficos de frequência, indicando a velocidade e direção dos ventos. Assim, foi possível concluir que há uma variação na velocidade dos ventos nos períodos de estiagem e de chuva, sendo este o de menor intensidade. Também foi possível concluir que a velocidade dos ventos é variável em função do período do dia, verificando uma maior intensidade no período da tarde. Os gráficos também apresentaram que há uma predominância dos ventos nos sentidos Leste, Nordeste e Sudeste, além de demonstrar que a direção e velocidade dos ventos sofre variação ao longo das estações do ano.

\section{Characterization of natural ventilation in Tangará da Serra/MT, Brazil from the perspective of civil construction}

\begin{abstract}
In Brazil, natural ventilation is an important bioclimatic strategy for promoting thermal comfort in buildings. This work aims to develop and evaluate the speed and direction of the winds in the municipality of Tangará da Serra - MT, in order to contribute as a scientific research collection for the design of bioclimatic architecture projects. For that, we used data from 2004 to 2014, provided by the National Institute of Meteorology - INMET, from which hourly averages were established for each day of the year. With this, the results were inserted in the WRPlot software, which provides frequency graphs, indicating the speed and direction of the winds. Thus, it was possible to conclude that there is a variation in the speed of the winds in periods of drought and rain, which is the least intense. It was also possible to conclude that the wind speed is variable depending on the period of the day, with greater intensity in the afternoon. The graphs also showed that there is a predominance of winds in the East, Northeast and Southeast directions, in addition to showing that the direction and speed of the winds varies over the seasons.
\end{abstract}

Keywords: Bioclimatic Strategies; Wind Rose; Climatology.

Topic: Desenvolvimento, Sustentabilidade e Meio Ambiente

Reviewed anonymously in the process of blind peer.

Mauricio Dallastra (iD)

Universidade do Vale do Taquari, Brasil

http://lattes.cnpq.br/5500532564363968

http://orcid.org/0000-0001-6392-9448

mauricio.dallastra@universo.univates.br

Andreia Fernandes da Silva (iD

Universidade do Estado de Mato Grosso, Brasil

http://lattes.cnpq.br/2642727360060591

http://orcid.org/0000-0002-9571-4481

andreiafernandes@fisica.ufmt.br

Rodrigo Spinelli (iD)

Universidade do Vale do Taquari, Brasil http://lattes.cnpq.br/7771857527009401 http://orcid.org/0000-0002-6323-706X rspinelli@univates.br
Received: 10/03/2020 Approved: 21/04/2020
Odorico Konrad iti

Universidade do Vale do Taquari, Brasil http://lattes.cnpq.br/9946679953072196 http://orcid.org/0000-0002-6968-7969

okonrad@univates.br
Referencing this:

DALLASTRA, M.; SILVA, A. F.; SPINELLI, R.; KONRAD, O.. Caracterização da ventilação natural em Tangará da Serra/MT, Brasil sob o viés da construção civil. Revista Ibero Americana de Ciências Ambientais, v.11, n.3, p.198-209, 2020. DOI: http://doi.org/10.6008/CBPC2179$\underline{6858.2020 .003 .0017}$

DOI: 10.6008/CBPC2179-6858.2020.003.0017 


\section{INTRODUÇÃO}

A ventilação natural desempenha papel fundamental na promoção de conforto ambiental nos edifícios. No Brasil, tal estratégia bioclimática é uma das mais importantes, visto a caracterização climática do país (LAMBERTS et al., 1997). Estudos desenvolvidos pela Comissão Americana da Ventilação, em 1916, comprovaram que o desconforto térmico em ambientes de trabalho reduziu o rendimento de trabalho físico entre 15 a 40\% quanto maior fosse a temperatura (FROTA et al., 2001). Além disto, há que se atentar à questão da síndrome do edifício doente, cujo conceito surge a partir do século XX quando, com o intuito de evitar a penetração da poluição externa e possibilitar o condicionamento ambiental interno, mudou-se os padrões arquitetônicos para edificações hermeticamente fechadas, as quais configuram uma atmosfera hostil a saúde do ser humano, como mostram pesquisas realizadas pela Organização Mundial da Saúde OMS (STERLING et al., 1991). Desta forma, mais que garantir um ambiente agradável, o emprego da ventilação natural para promoção de conforto térmico tem como intuito incrementar a produtividade, segurança e saúde (física e mental) dos usuários.

No Brasil, estudos desenvolvidos apontam resultados satisfatórios no que se refere a aplicação da ventilação natural em edifícios, tanto nos aspectos relacionados ao conforto térmico quanto de eficiência energética, enfatizando a importância da ventilação natural enquanto estratégia passiva de condicionamento ambiental (LABAKI et al., 1998; SORGATO et al., 2016; FLORES-LARSEN et al., 2019; COSTA et al., 2019).

A ventilação natural pode ser incrementada nos edifícios a partir da geometria e posicionamento adequado do edifício e das aberturas, além do emprego de elementos construtivos que desempenhem a função de captação e condução do fluxo de ar, os quais também mostram-se eficazes, especialmente em locais de clima quente e úmido (PAPAKONSTANTINOU et al., 2000; LÔBO et al., 2003).

Contudo, promover conforto a partir da ventilação natural exige que outras variáveis climáticas sejam consideradas, tais como temperatura e umidade relativa do ar, as quais podem aquecer o ar e comprometer a eficiência dessa estratégia bioclimática. Em Tangará da Serra - MT, cuja característica climática demonstra variação de até $30 \%$ nos índices de umidade relativa do ar, a ventilação natural deve ser aplicada em aproximadamente $23 \%$ dos dias do ano e estar associada a outras estratégias bioclimáticas para que seja satisfatória, no âmbito do conforto térmico em edifícios (DALLASTRA et al., 2019).

Tangará da Serra/MT, assim como outros municípios mato-grossenses, não possui estudos específicos acerca da ventilação natural sob o viés da construção civil, sendo restrito apenas à aspectos direcionados ao setor da agricultura (DALLACORT et al., 2010). Assim, este trabalho se justifica por contribuir para o acervo científico no âmbito da construção civil, de modo que sirva como instrumento para nortear as ações na concepção de projetos arquitetônicos bioclimáticos que venham ao encontro das proposições do desenvolvimento sustentável e eficiência energética.

Por fim, esta pesquisa tem como objetivo desenvolver e analisar a rosa dos ventos predominantes no município de Tangará da Serra/MT a partir da coleta de dados de direção e velocidade, tendo como objetivo específico apresentar as direções e velocidades do vento registradas no município ao longo do ano 
e períodos sazonais e diários.

\section{METODOLOGIA}

\section{Local da pesquisa}

Este estudo aborda sobre as características da ventilação natural na cidade de Tangará da Serra, a qual está localizada geograficamente entre as serras Tapirapuã e Parecis, no estado de Mato Grosso, Brasil (Figura 1).



Figura 1: Localização do estado de Mato Grosso em relação ao país e localização de Tangará da Serra em relação ao estado, respectivamente.

O munícipio, com população estimada de 101.764 habitantes, é o sexto mais populoso do estado, de acordo com o Instituto Brasileiro de Geografia e Estatística - IBGE (2018). O setor da construção civil, por sua vez, apresenta um cenário favorável, contando com aproximadamente 105 empresas regulamentadas atuando neste segmento, sendo que aproximadamente $80 \%$ destas atuam diretamente com projetos arquitetônicos e execução de obras. Possui ainda mais de 17 empresas, além de profissionais autônomos, que prestam serviços nas áreas de arquitetura. No ramo da educação, o município possui duas instituições de ensino que contam com cursos de engenharia civil, sendo uma delas estadual e outra de iniciativa privada sendo, portanto, um município com potencial para o desenvolvimento de pesquisas na área da construção civil (IBGE, 2018).

O clima típico da região é o tropical quente e subúmido, tendo períodos bem marcados de chuva e seca ao longo do ano (DALLACORT et al., 2011), isto se deve ao fato de o município estar localizado no bioma Cerrado, onde as chuvas se concentram nas estações de primavera e verão (SOUSA et al., 2002). No que se refere ao índice pluviométrico, Tangará da Serra/MT, apresenta duas estações bem definidas: o período seco, entre maio a setembro; e chuvoso, entre outubro e abril, sendo janeiro a março o período de maior ocorrência de precipitação (DALLACORT et al., 2011). De acordo com Dallastra et al. (2019) as temperaturas mínimas $(16,96 \stackrel{\circ}{\circ})$ e máxima $(33,68 \stackrel{\circ}{\circ})$ compreendem, respectivamente, aos períodos de seca e chuva, conforme exposto na Figura 2. 


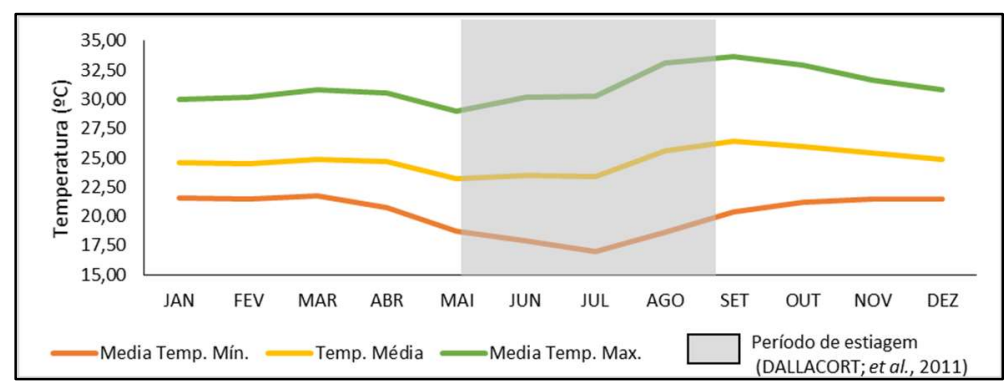

Figura 2: Gráfico das temperaturas mínima, média e máxima em Tangará da Serra. Fonte: DALLASTRA et al. (2019).

\section{Materiais e métodos}

Para atender os propósitos deste trabalho foi coletado a direção e velocidade dos ventos a fim de desenvolver a rosa dos ventos predominantes do município. Para isso utilizou-se do banco de dados fornecidos pelo Instituto Nacional de Meteorologia - INMET, cuja estação meteorológica automática está localizada em terreno plano e com ampla visão do horizonte, na Universidade do Estado de Mato Grosso UNEMAT, Campus Tangará da Serra, latitude $14^{\circ} 39^{\prime}$ S, longitude $57^{\circ} 25^{\prime} 53,5^{\prime \prime} \mathrm{W}$, com altitude de 321,5 metros. A estação está equipada com um anemômetro instalado a 10 metros de altura em relação ao solo, o qual registra a média horária da velocidade e a direção dos ventos incidentes na região ao longo dos últimos anos. Além disto, os resultados foram comparados com pesquisas já desenvolvidas sobre a incidência de ventos no local em outros períodos (DALLACORT et al., 2010).

Os dados disponibilizados pelo INMET compreendem os registros de 2004 a 2019 e, a partir destes realizou-se uma análise prévia dos dados, onde se verificou que a partir de 2015 a 2019, os resultados apresentam inconsistências e valores nulos, fornecendo um ou mais meses onde não houveram registros das variáveis de ventilação ou ainda, apresentam valores repetidos ao longo de muitas horas e dias. Portanto, estes dados foram desconsiderados para a realização deste trabalho. Assim, este artigo apresenta a caracterização dos ventos de 2004 a 2014. Para a caracterização da direção do vento adotou-se como parâmetro as medidas em ângulo, conforme expostos na Tabela 1.

Tabela 1: Direção do vento de acordo com os ângulos de incidência.

\begin{tabular}{|l|l|l|}
\hline Direção dos ventos & Símbolo & Graus (o) \\
\hline Norte & N & 0 a 23 e 337 a 360 \\
\hline Nordeste & NE & 24 a 68 \\
\hline Leste & E & 69 a 113 \\
\hline Sudeste & SE & 114 a 158 \\
\hline Sul & S & 159 a 203 \\
\hline Sudoeste & SW & 204 a 248 \\
\hline Oeste & W & 249 a 293 \\
\hline Noroeste & NW & 294 a 338 \\
\hline
\end{tabular}

Fonte: Dallacort et al. (2010).

De posse dos dados referentes a velocidade $(\mathrm{m} / \mathrm{s})$ e direção correspondente a cada dia, hora e ano (2004 a 2014), estabeleceu-se a média para cada hora de cada dia entre os anos analisados. Estes dados foram, então, inseridos no software WRPLOT View - Freeware Wind Rose Plots for Meteorological Data, desenvolvido pelo Lakes Environmental. Este gera gráficos de frequência, a partir da importação de uma planilha em formato .xls, dispondo os dados de entrada em um diagrama, apresentando a direção 
predominante dos ventos, e porcentagem das velocidades verificadas, possibilitando, assim, a análise de forma integral ou a partir de meses e horários específicos.

No que se refere à velocidade do vento o software atribui, de acordo com os dados de entrada, cores que correspondem a faixa de valores, em metros por segundo, sendo: verde-claro para ventos entre 0,50 a $2,10 \mathrm{~m} / \mathrm{s}$; amarelo para ventos entre 2,10 e 3,60 m/s; vermelho, entre 3,60 a 5,70 m/s; azul, entre 5,70 a 8,80 $\mathrm{m} / \mathrm{s}$; verde entre 8,80 a $11,10 \mathrm{~m} / \mathrm{s}$; e ciano para velocidades superiores a $11,10 \mathrm{~m} / \mathrm{s}$. Os períodos de calmaria compreendem registros inferiores a $0,50 \mathrm{~m} / \mathrm{s}$ e, portanto, não são representados na rosa dos ventos.

Inicialmente gerou-se a rosa dos ventos para todos os dias e horas das médias calculadas. Em seguida realizou-se a seleção dos meses de maio a setembro, os quais compreendem o período de estiagem, e também dos meses de outubro a abril, os quais se referem ao período de chuvas no município (DALLACORT et al., 2011). Posteriormente, realizou-se a plotagem da rosa dos ventos para cada estação do ano. Por fim, realizou-se a análise a partir de horas específicas, a fim de verificar o comportamento da ventilação nas madrugadas e nos períodos matutino, vespertino e noturno, adotando os intervalos de 20 às $01 \mathrm{~h}$; das 02 às 07h; 08 às 13h; 14 às 19h, respectivamente. Vale ressaltar que os horários disponibilizados pelo INMET apresentam os registros em hora UTC e, em função da latitude do município corresponder ao fuso horário UTC -4 , os dados para análise por períodos diários foram corrigidos para a hora local.

\section{RESULTADOS E DISCUSSÃO}

A Figura 3) apresenta a velocidade dos ventos a partir da média das médias mensais, demonstrando que os ventos de maior intensidade (acima de $2,5 \mathrm{~m} / \mathrm{s}$ ) correspondem aos meses de agosto $(2,58 \mathrm{~m} / \mathrm{s}$ ), setembro $(2,65 \mathrm{~m} / \mathrm{s})$ e novembro $(2,50 \mathrm{~m} / \mathrm{s})$; os meses cuja velocidade do vento apresentou os menores valores são, respectivamente, fevereiro $(1,87 \mathrm{~m} / \mathrm{s})$ e Janeiro $(1,97 \mathrm{~m} / \mathrm{s})$. Os demais meses do ano apresentam velocidades entre $2,10 \mathrm{~m} / \mathrm{s}$ (maio) e $2,40 \mathrm{~m} / \mathrm{s}$ (junho).

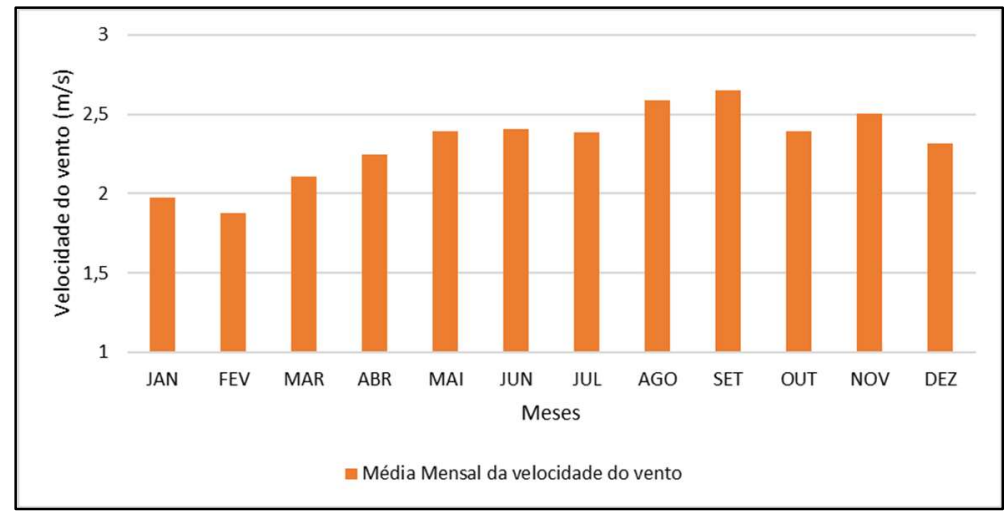

Figura 3: Média da velocidade do vento por mês.

Estes resultados são semelhantes aos de Dallacort et al. (2010), os quais afirmam que os ventos de maior velocidade são os verificados no período diurno e noturno entre julho e setembro. Também vem ao encontro da pesquisa realizada por Santanna et al. (2008) para a cidade de Cuiabá (capital do estado de Mato Grosso), os quais identificaram que na primavera há uma predominância de ventos de maior intensidade.

Na Figura 4 estão expostos os resultados das médias calculadas para a direção do vento, 
demonstrando haver uma variação ao longo dos meses: de dezembro a fevereiro os ventos correspondem à direção nordeste (NE); em março à direção leste (E); abril corresponde à direção sudeste (SE); de maio a agosto os ventos incidem na direção leste (E); setembro e outubro na direção sudeste (SE); e, por fim, predominam à leste $(\mathrm{E})$ no mês de novembro.

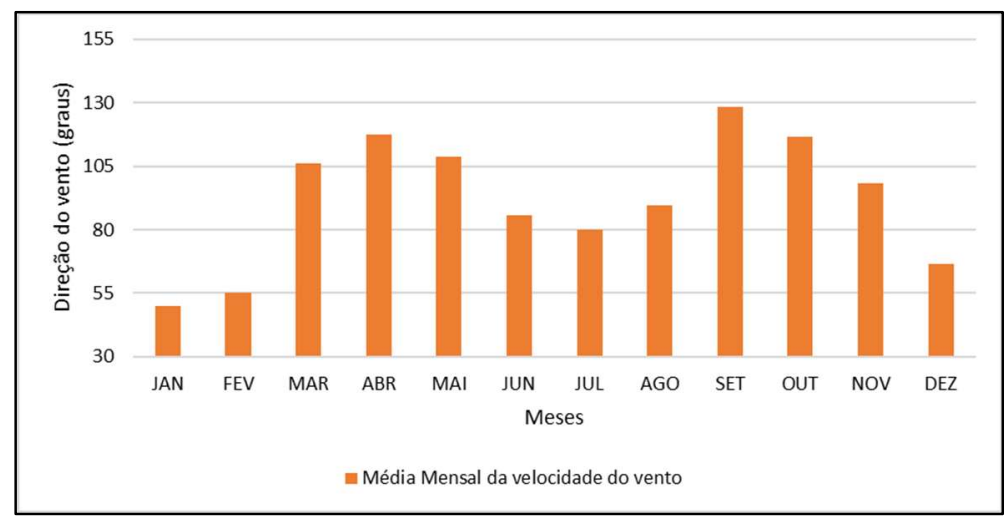

Figura 4: Média da direção do vento por mês.

A Figura 5 apresenta a rosa dos ventos que compreende aos dados das médias para todos os anos (de 2004 a 2014). Nesta, os mesmos resultados observados nas Figuras 2 e 3 podem ser verificados, demonstrando haver, ainda que com menor frequência, registros de ventilação a Norte, Sul e Sudoeste. Ainda na Figura 5 verifica-se a inexistência de ventos com velocidades acima de 5,70 m/s, predominando velocidades entre 2,10 a $3,60 \mathrm{~m} / \mathrm{s}$.

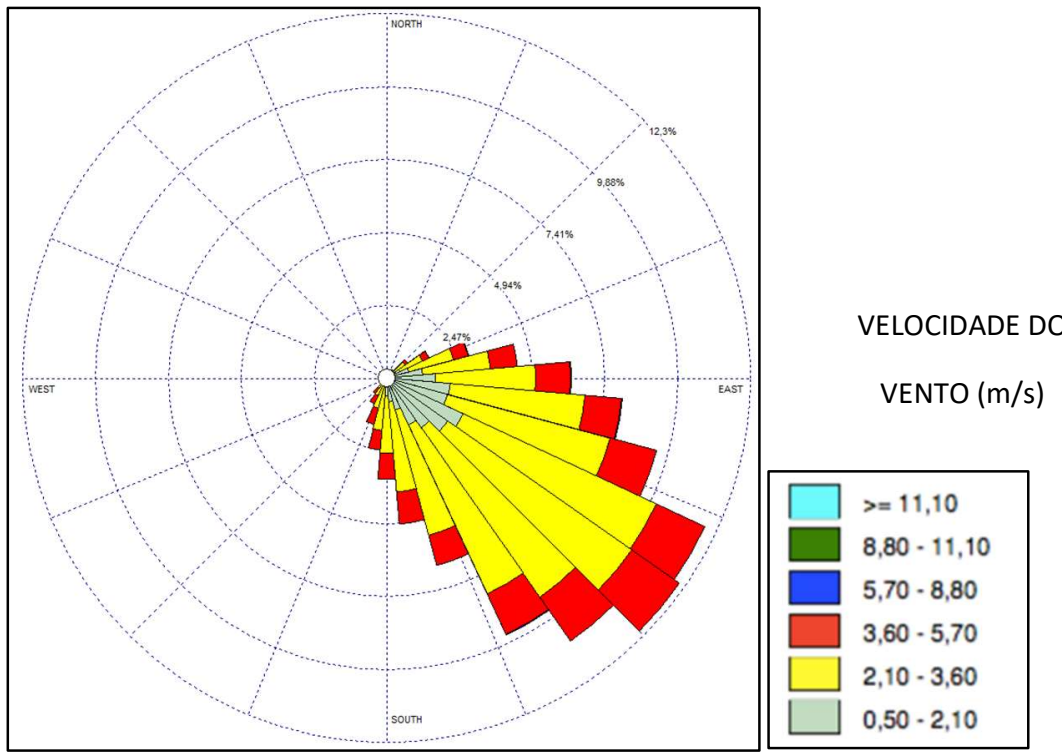

Figura 5: Rosa dos ventos a partir da média horária de todos os anos (2004 a 2014).

Estes dados vêm ao encontro do que afirma Amarante et al. (2001), os quais identificaram o potencial eólico brasileiro para fins energéticos a partir das médias de velocidade dos ventos nas regiões brasileiras. $O$ centro-oeste do Brasil apresentou o menor potencial, uma vez que se verificou uma média anual de velocidade dos ventos (a 50 metros de altura do solo) da ordem de aproximadamente $5 \mathrm{~m} / \mathrm{s}$.

A Figura 6 apresenta os dados que compreendem os períodos de estiagem, os quais coincidem com o período de inverno no hemisfério sul. De acordo com os dados, as velocidades mais intensas verificadas 
(entre 5,70 e $8,80 \mathrm{~m} / \mathrm{s}$ ) predominam no sentido leste $(E)$, enquanto a maior ocorrência, dada em porcentagem, aponta para o sentido sudeste (SE), com velocidade entre 0,50 a 5,70 m/s. É neste período que são verificadas também as maiores amplitudes térmicas na localidade (DALLASTRA et al., 2019) e também a maior velocidade dos ventos, se comparado ao período chuvoso.

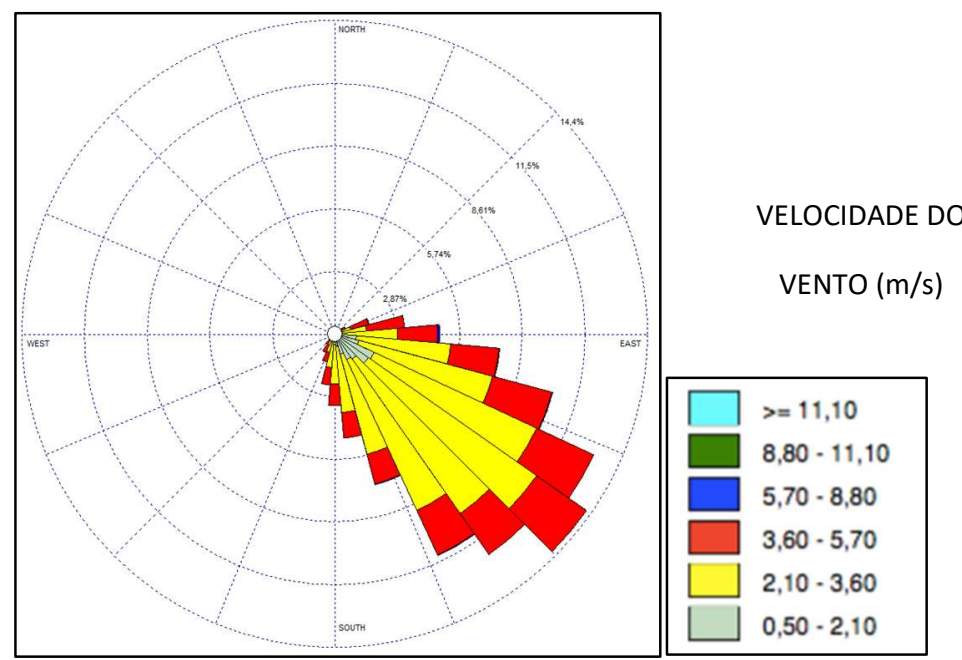

Figura 6: Rosa dos ventos correspondente ao período de estiagem.

Já a Figura 7 apresenta os dados referentes ao período chuvoso, o qual coincide com o período de verão e outono no hemisfério sul. De acordo com os dados, a maior ocorrência de vento, dada em porcentagem, predomina no sentido Sudeste (SE), oscilando entre 0,50 a 5,70 m/s. Nota-se, ainda, que neste gráfico os ventos têm uma maior dispersão, oscilando entre as direções nordeste (NE) e sudoeste (SW), se comparado à rosa dos ventos no período de estiagem.

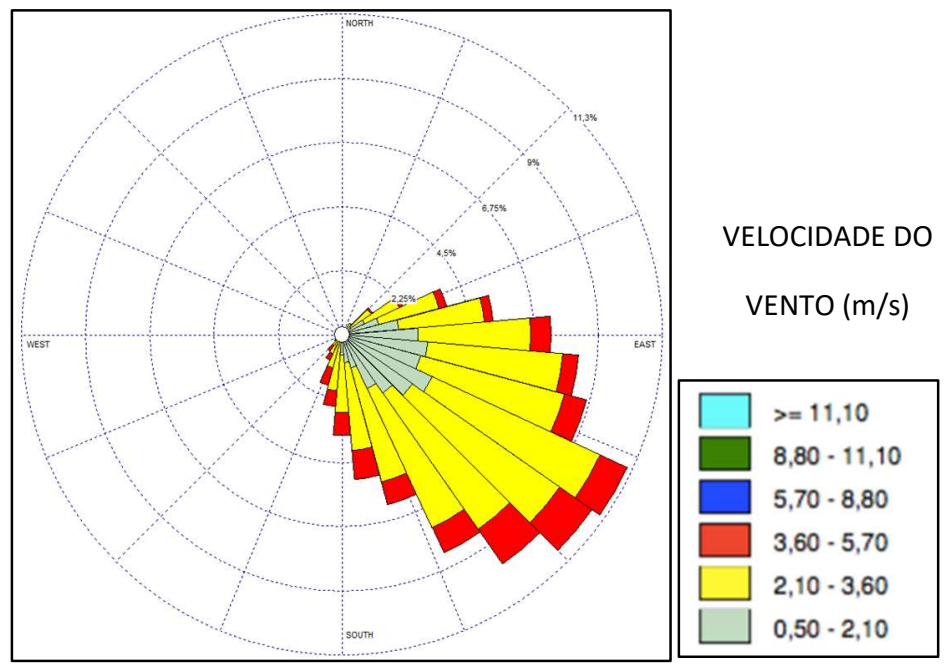

Figura 7: Rosa dos ventos correspondente ao período chuvoso.

A Figura 8 apresenta, respectivamente e de forma mais específica, a velocidade e direção dos ventos nas estações outono, inverno, primavera e verão demonstrando haver oscilação nas frequências, velocidades e direção dos ventos, de acordo com cada período: no outono, não há ocorrência de calmaria e predominam os ventos cuja direção compreende o sentido sudeste (SE); no inverno os ventos ocorrem com maior frequência no sentido sudeste (SE), e velocidades entre 5,70 e $8,80 \mathrm{~m} / \mathrm{s}$ nos sentidos leste (E) e sudeste (SE); 
na primavera os ventos ocorrem a sudeste (SE), predominando velocidades entre 2,10 a 3,60 m/s; enquanto no verão os registros apontam uma maior ocorrência na direção sudeste (SE). Dados semelhantes também foram identificados por Munhoz et al. (2008) para a cidade de Ituverava, São Paulo. A rosa dos ventos de cada estação também demonstra haver uma menor dispersão nas direções do vento no período de outono, contrapondo o período da primavera, o qual sugere que o vento oscile a direção entre o nordeste (NE) e sudoeste (SW).
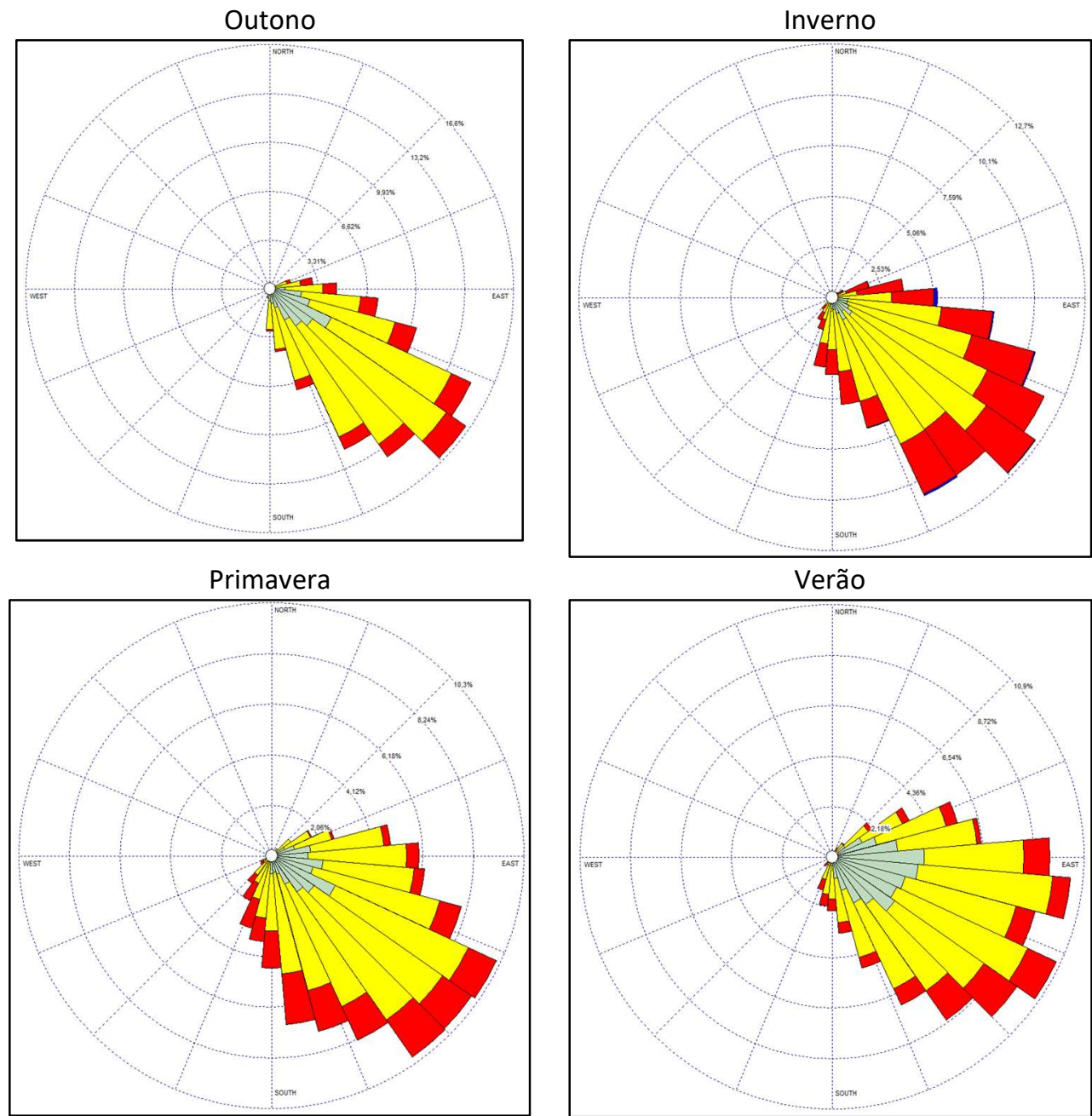

$\square>=11,10$
$8,80 \cdot 11,10$
$5,70 \cdot 8,80$
$3,60 \cdot 5,70$
$2,10 \cdot 3,60$
$\square, 50 \cdot 2,10$

VELOCIDADE DO

$\operatorname{VENTO}(\mathrm{m} / \mathrm{s})$

Figura 8: Rosa dos ventos para cada as estações Outono, Inverno, Primavera e Verão, respectivamente.

A Figura 9 apresenta os valores referentes a porcentagem de ocorrência das velocidades dos ventos de acordo com as estações do ano, demonstrando que no inverno há registros de ventos com maior velocidade (59,80\% de ventos entre 2,10 a $3,60 \mathrm{~m} / \mathrm{s}, 30,50 \%$ para os ventos entre 3,60 a $5,70 \mathrm{~m} / \mathrm{s})$. Ainda no inverno, embora que com uma porcentagem de apenas $2 \%$ do período, há ocorrência de ventos entre 5,70 a $8,80 \mathrm{~m} / \mathrm{s}$. No verão os ventos com velocidades entre 0,50 a $2,10 \mathrm{~m} / \mathrm{s}$ correspondem a $32,80 \%$ do período e os ventos entre 2,10 a $3,60 \mathrm{~m} / \mathrm{s}$ equivalem a $54,40 \%$. Na primavera verifica-se que as velocidades oscilam entre 0,50 a $5,70 \mathrm{~m} / \mathrm{s}$, sendo que os ventos mais intensos do período compreendem $30,50 \%$ do período. Por 
fim, o outono apresenta $65 \%$ do período com ventos entre 2,10 a 3,60 m/s.

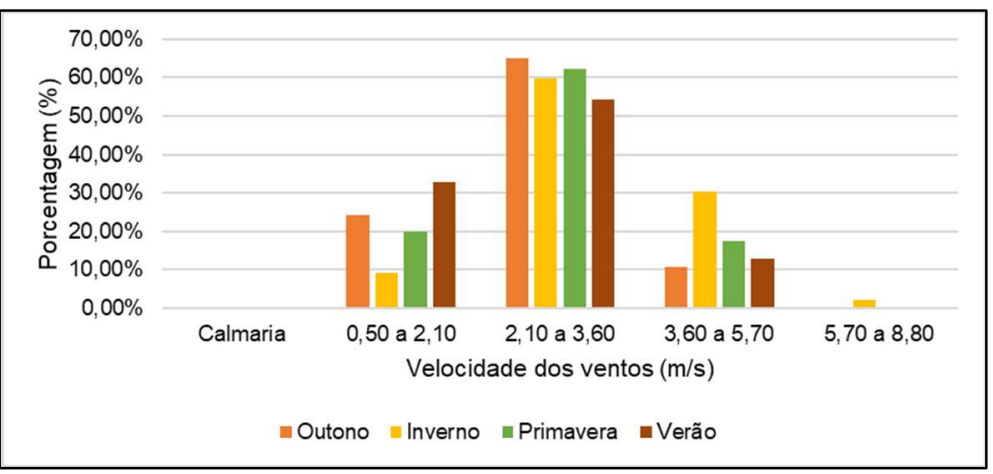

Figura 9: Gráfico das porcentagens da velocidade dos ventos para as estações do ano.
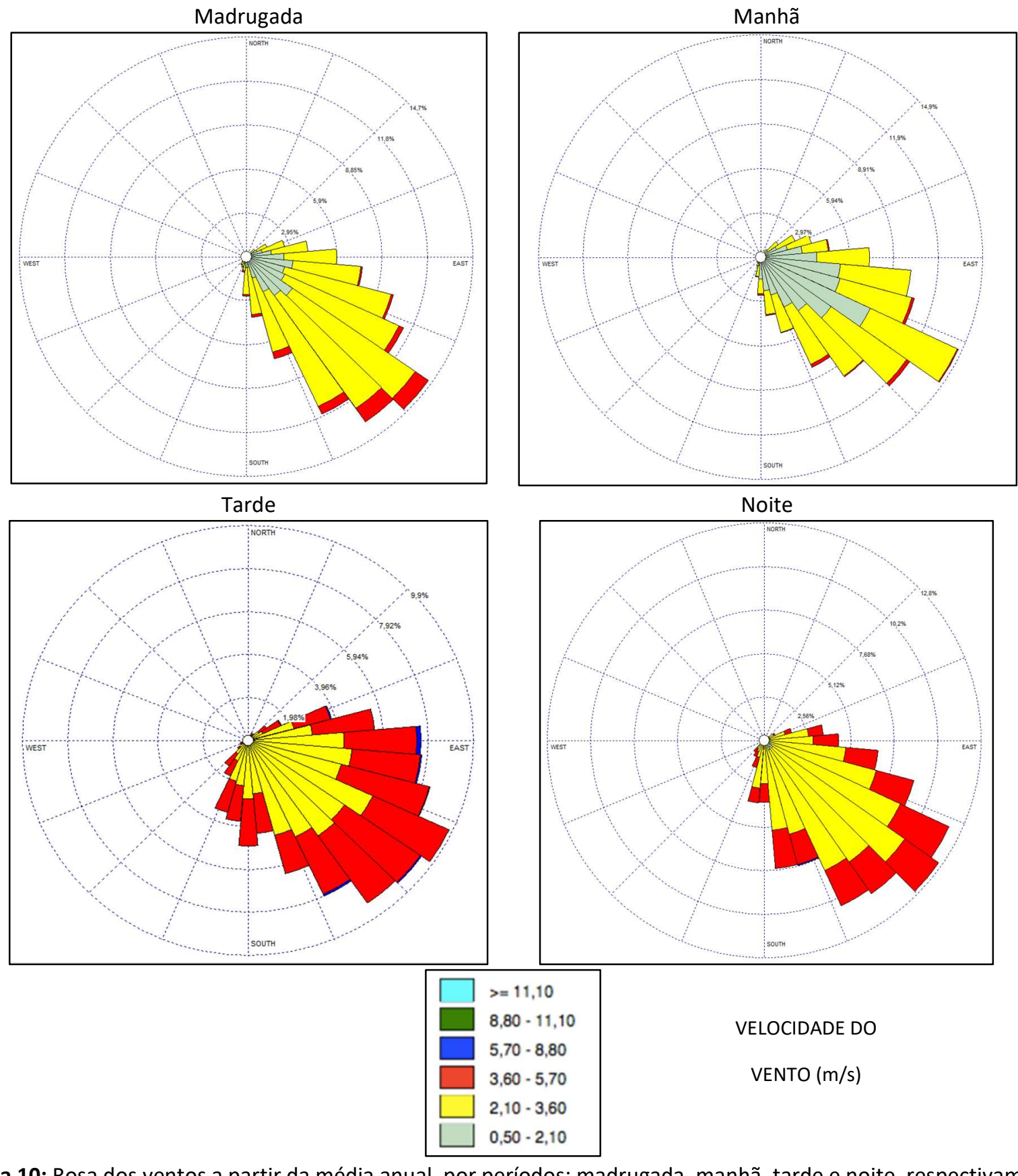

Figura 10: Rosa dos ventos a partir da média anual, por períodos: madrugada, manhã, tarde e noite, respectivamente.

A Figura 10 demonstra, respectivamente, a rosa dos ventos definida de acordo com as médias anuais analisadas por período do dia: madrugada, manhã, tarde e noite, sugerindo que as maiores velocidades de 
vento registradas (da ordem de 3,60 a 5,70 m/s) ocorrem nos períodos da tarde e noite. Estes resultados corroboram com Alves et al. (2011) e Dallacort et al. (2010) que também identificaram uma diferença na velocidade do vento entre os períodos diurnos e noturnos. Isto é justificado em função do solo, aquecido durante o dia, também promover aquecimento no ar, o qual tende a ascender, dando lugar a massa de ar frio, gerando uma diferença térmica e, consequentemente, um gradiente de pressão, o qual promove a movimentação do ar, resultando em velocidades menores. Durante a noite este fenômeno acontece de forma menos significativa e, portanto, a velocidade dos ventos tende a ser menor (SENAMBI, 2004). Em todos os períodos se verifica que há uma predominância dos ventos na direção sudeste (SE), ocorrendo ainda velocidades entre 5,70 a $8,80 \mathrm{~m} / \mathrm{s}$ no período da tarde, nas direções sudeste (SE) e leste (E).

Por fim, a Figura 11 apresenta, respectivamente, as porcentagens de ocorrência dos ventos durante a madrugada, manhã, tarde e noite. Nesta, verifica-se que não há ocorrências de calmaria em nenhum dos períodos. Quanto às velocidades superiores a 3,60 m/s verifica-se que é durante a tarde que estas ocorrem, enquanto as menores velocidades registradas predominam durante a madrugada e manhã. Estes resultados corroboram com Dallacort et al. (2010) os quais apontam como média anual da velocidade dos ventos os valores de $3,4 \mathrm{~m} / \mathrm{s}$ e $2,5 \mathrm{~m} / \mathrm{s}$ para os períodos diurnos e noturnos, respectivamente.

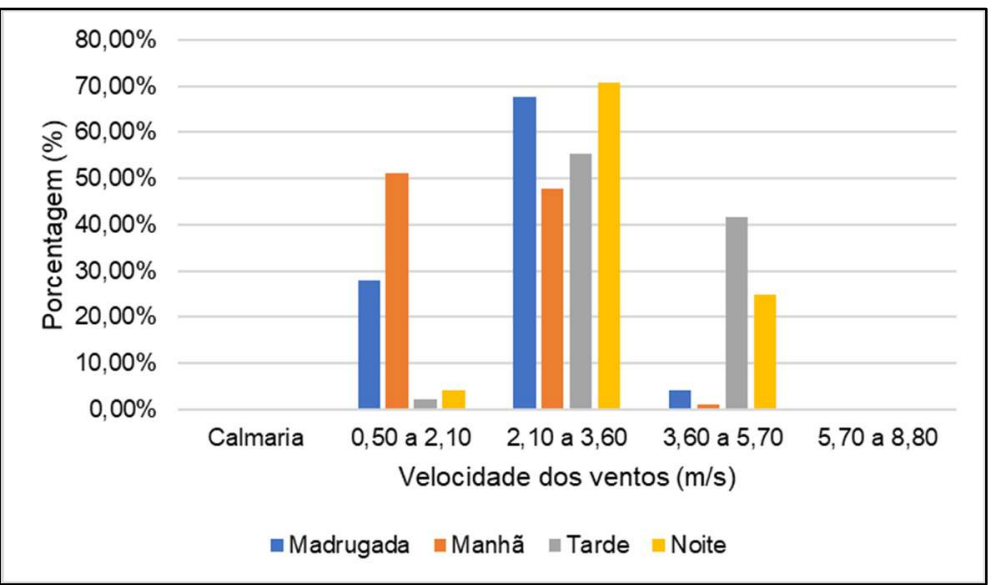

Figura 11: Gráfico das velocidades registradas por períodos: madrugada, manhã, tarde e noite, respectivamente, a partir da média.

A ventilação natural é fundamental para os edifícios uma vez que desempenha a função de renovação e higienização do ar, além de ser responsável por promover o resfriamento psicofisiológico e convectivo. Para tanto, propõe-se o uso de sistemas tais como: o efeito chaminé, pelo qual o ar frio, cuja densidade é maior, exerce pressão positiva, tendendo a descer, enquanto o ar quente, cuja densidade é menor, exerce pressão negativa, tendendo a subir, criando correntes de convecção; e a ventilação cruzada, que possibilita a remoção do calor, acelerando as trocas por convecção, além de elevar os níveis de evaporação, melhorando a sensação térmica no ambiente interno (KOWALTOWSKI et al., 1993; LÔBO et al., 2003; MANZANOAGUGLIARO et al., 2015).

A ventilação natural é, ainda, uma das estratégias bioclimáticas mais importantes para o clima da cidade de Tangará da Serra/MT, sendo recomendada, de maneira isolada, entre os meses de outubro a maio, e combinada com resfriamento evaporativo e alta inércia térmica dos elementos construtivos ao longo de 
todos os meses do ano (DALLASTRA et al., 2019). Assim, faz-se necessário considerar as direções predominantes, de modo a priorizá-las na implantação de aberturas para que o vento penetre o edifício. As aberturas devem ser implantadas nas fachadas sudeste (SE) e leste (E) e, de modo a proporcionar a ventilação cruzada, sugere-se também a instalação de aberturas nas fachadas opostas (noroeste e oeste). Aberturas voltadas a sul (E) e nordeste (NE) também são soluções interessantes, especialmente no período de verão. Contudo, devem ser adotadas de modo associado a alta inércia térmica e resfriamento evaporativo, os quais podem ser verificados em função das propriedades termofísicas dos materiais utilizados para envoltória e na implantação de vegetação e espelhos d'água para aumentar a umidade do vento incidente (MANZANOAGUGLIARO et al., 2015). Esses resultados corroboram com estudos realizados na cidade de Cuiabá, quanto a promoção de conforto térmico por meio da ventilação e estratégias naturais de condicionamento climático (NASCIMENTO et al., 2019).

Estudos realizados com dados de 2003 a 2008 (DALLACORT et al., 2010) apresentaram resultados que indicam haver uma predominância de ocorrência de ventilação nas direções norte (N) e nordeste (NE), contudo, neste trabalho verificou-se haver uma predominância nos sentidos leste (E), nordeste (NE) e sudeste (SE). Esta variação pode ser justificada em função do período analisado ser mais extenso, sendo possivelmente mais representativo. Ainda, os resultados foram semelhantes aos obtidos nesta pesquisa quanto a direção dos ventos em fevereiro, abril, junho e dezembro, apresentando divergência nos demais meses. As velocidades médias em ambos os estudos apresentaram resultados semelhantes, apontando agosto e setembro como os meses com maior velocidade do vento registrada.

\section{CONCLUSÕES}

Com este artigo pode-se contextualizar questões relacionadas a ventilação natural como estratégia para promoção de conforto térmico em ambientes construídos, ressaltando a importância das questões climáticas para a construção civil. Verificou-se que os ventos incidem com mais intensidade nos períodos secos do ano enquanto no período chuvoso as velocidades registradas apresentaram os menores valores. Pode-se concluir ainda que há uma predominância dos ventos nos sentidos leste (E), sudeste (SE) e nordeste (NE) ao longo dos meses analisados.

Este trabalho serve de aporte para a elaboração de projetos arquitetônicos que sejam coerentes à realidade climática de Tangará da Serra/MT, garantindo que as edificações possuam ambientes confortáveis e eficientes energeticamente, uma vez que o uso de instrumentos artificiais para condicionamento ambiental poderá ser mitigado.

\section{REFERÊNCIAS}

ALVES, E. D. L.; SILVA, S. T.. Direção e Velocidade do Vento Em Uma Floresta De Transição Amazônia-Cerrado No Norte De Mato Grosso, Brasil. Boletim Goiano de Geografia, v.31, n.1, p.7788, 2011.
AMARANTE, O. A.; ZACK, M. B. J.; SÁ, A. L.. Atlas do potencial eólico brasileiro. Brasília: MME; Rio de Janeiro: Eletrobrás, 2001

COSTA, M. L.; FREIRE, M. R.; KIPERSTOK, A.. Strategies for thermal comfort in university buildings: The case of the faculty of architecture at the Federal University of Bahia, 
Brazil. Journal of Environmental Management, v.239, n.2, p.114-123, 2019. DOI: http://doi.org/10.1016/i.jenvman.2019.03.004

DALLACORT, R.; MARTINS, J. A.; INOUE, M. H.; FREITAS, P. S. L.; COLETTI, A. J.. Distribuição das chuvas no município de Tangará da Serra, médio norte do Estado de Mato Grosso, Brasil. Acta Scientiarum. Agronomy, Maringá, v.33, n2, p.193-200, 2011.

DALLACORT, R.; MOREIRA, P. S. P.; INOUE, M. H.; SILVA, D. J.; CARVALHO, I. F.; SANTOS, C.. Wind speed and direction characterization in Tangará da Serra, Mato Grosso state, Brazil. Revista Brasileira de Meteorologia, São Paulo, v.25, n.3, p.359-364, 2010.

DALLASTRA, M.; SILVA, A. F.; SPINELLI, R.; DALLACORT, R.; DALZOCHIO, M. S.; KONRAD, O.. Bioclimatic strategies for the city of Tangará da Serra/MT-Brazil. Revista Brasileira de Climatologia, v.25, n.15, p.399-423, 2019.

FLORES-LARSEN, S.; FILIPPÍN, C.; BAREA, G.. Impact of climate change on energy use and bioclimatic design of residential buildings in the 21st century in Argentina. Energy and Buildings, v.184, p.216-229, 2019. DOI: http://doi.org/10.1016/j.enbuild.2018.12.015

FROTA, A. B.; SCHIFFER, S. R.. Manual de conforto térmico: arquitetura, urbanismo. 5 ed. São Paulo: Studio Nobel, 2001.

IBGE. Instituto Brasileiro de Geografia e Estatística. Cidades. Tangará da Serra: IBGE, 2018.

KOWALTOWSKI, D. C. C. K.; LABAKI, L. C.. O Projeto Arquitetônico e o Conforto Ambiental: Necessidade de uma Metodologia. In: ENCONTRO NACIONAL DE TECNOLOGIA DO AMBIENTE CONSTRUÍDO, AVANÇOS EM TECNOLOGIA E GESTÃO DA PRODUÇÃO DE EDIFICAÇÕES, 5. Anais. São Paulo, 1993. p.785-794.

LABAKI, L. C.; KOWALTOWSKI, D. C. C. K.. Bioclimatic and Vernacular Design in Urban Settlements of Brazil. Building and Environment, v.33, n.1, p.63-77, 1998.

LAMBERTS, R.; DUTRA, L.; PEREIRA, F.. Eficiência Energética na Arquitetura. São Paulo: PW, 1997.
LÔBO, D. G. F.; BITTENCOURT, L. S.. A influência dos captadores de vento na ventilação natural de habitações populares localizadas em climas quentes e úmidos. Ambiente Construído, v.3, n.2, p.57-67, 2003.

MANZANO-AGUGLIARO, F.; MONTOYA, F. G.; ORTEGASABIO, A.; CRUZ-GARCÍA, A.. Review of bioclimatic architecture strategies for achieving thermal comfort. Renewable and Sustainable Energy Reviews, v.49, p.736-55, 2015. DOI: http://dx.doi.org/10.1016/i.rser.2015.04.095

MUNHOZ, F. C.; GARCIA, A.. Caracterização da velocidade e direção predominante dos ventos para a localidade de Ituverava-SP. Rev. Bras. Meteorol., São Paulo, v.23, n.1, p.30-34, 2008

NASCIMENTO, M. J. S.; NOVAIS, J. W. Z.; FERNANDES, T.. Conforto termal como parâmetro de qualidade no trabalho em uma indústria de ração animal. Revista Ibero Americana de Ciências Ambientais, v.10, n.6, p.154-162, 2019. DOI: http://doi.org/10.6008/CBPC2179-6858.2019.006.0014

PAPAKONSTANTINOU, K. A.; KIRANOUDIS, C. T.; MARKATOS, N. C.. Numerical simulation of air flow field in single-sided ventilated buildings. Energy and Buildings, v.33, n.1, p.4148,2000

SANTANNA, F. B.; ARRUDA, P. H. Z.; FARIA, J. L. B.; NOGUEIRA, J. S.. Estudo preliminar da velocidade e direção dos ventos, em Cuiabá, MT, Brasil. Revista Brasileira de Agrometeorologia, v.16, n.2, p.175-180, 2008.

SENAMBI. Serviço Nacional de Meteorologia e Hidrologia Del Peru. Aprendendo Meteorologia. SENAMBI, 2004.

SORGATO, M. J.; MELO, A. P.; LAMBERTS, R.. The effect of window opening ventilation control on residential building energy consumption. Energy and Buildings, v.133, p.1-13, 2016. DOI: http://dx.doi.org/10.1016/j.enbuild.2016.09.059

SOUSA, P.; NERY, J. T.. Análise da variabilidade annual e interannual da precipitação pluviométrica da região de Manuel Ribas, Estado do Paraná. Acta Scientiarum.

Agronomy, v.24, n.6, p.1707-1713, 2002.

STERLING, T. D.; COLLET, C.; RUMEL, D.. A epidemiologia dos 'edifícios doentes'. Rev. Saúde Públ., São Paulo, v.25, p.5663, 1991.

A CBPC - Companhia Brasileira de Produção Científica (CNPJ: 11.221.422/0001-03) detém os direitos materiais desta publicação. Os direitos referem-se à publicação do trabalho em qualquer parte do mundo, incluindo os direitos às renovações, expansões e disseminações da contribuição, bem como outros direitos subsidiários. Todos os trabalhos publicados eletronicamente poderão posteriormente ser publicados em coletâneas impressas sob coordenação da Sustenere Publishing, da Companhia Brasileira de Produção Científica e seus parceiros autorizados. Os (as) autores (as) preservam os direitos autorais, mas não têm permissão para a publicação da contribuição em outro meio, impresso ou digital, em português ou em tradução. 